\title{
Can compulsory removal ever be justified for adults who are mentally competent?
}

\author{
David A Greaves University College, Swansea
}

\begin{abstract}
Author's abstract
Section 47 of the National Assistance Act is controversial in that it makes provision for the compulsory removal and care of mentally competent adults in certain limited circumstances. A case is described in which it is argued that compulsory management could be justified. This is because the diversity and potentially conflicting nature of the relevant considerations involved in this and a restricted range of other cases, defies their being captured in any wholly rational moral scheme. It follows that if the law is to be both sensitive and just it cannot always provide definitive guidance as to how the community doctor, as the designated decision-maker, should act. The acceptance of his or her judgement is therefore necessary and depends for its proper working on trust, which can only be gained through compassion and respect for the patients concerned.
\end{abstract}

\section{Introduction}

Compulsory removal for medical treatment and care is usually considered to be justified only for those who lack capacity and are therefore deemed incompetent to make decisions on their own behalf, and then only in particular circumstances. Those falling into such a category are restricted to two main groups, children and those with serious mental illness or handicap. However Section 47 of the National Assistance Act (1948 amended 1951) allows for the compulsory removal of a further group of people who:

(a) are suffering from grave chronic disease, or being aged, infirm or physically incapacitated, are living in insanitary conditions, and

(b) are unable to devote to themselves, and are not receiving from other persons, proper care and attention.

Although this section is not widely used (having been conceived in the inter-war period when suicide was a crime) it has nevertheless been criticised on a number of counts, most seriously for what is seen as its unacceptable reliance on medical paternalism and

\section{Key words}

Right to refuse treatment; old age. consequent disrespect for patient autonomy in cases where the patient's incompetence does not have to be demonstrated or is uncertain. This has led to demands that the law should be repealed, or at least be amended (1).

The present concern is not therefore, with the provisions of Section 47 as a whole (which most would agree are drawn too widely for present-day purposes), but only with whether mentally competent people should ever be removed compulsorily on medical grounds. And this will be considered through the description and analysis of a case in which a decision had to be made about compulsory removal, and in which it will be suggested that references to medical paternalism, patient autonomy and the assessment of incompetence do not do justice to the moral issues which are at stake. It is argued that to analyse Section 47 solely in these terms is inadequate, and the consequences for our understanding of ethics and the role of law in this area are considered.

\section{The case}

$\mathrm{Mr}$ Hall (a pseudonym) was 75 years old. He was involved in an accident whilst riding his bicycle, and taken to the hospital casualty department by ambulance. He was found to have sustained a serious fracture of the knee joint. He was advised that he needed an operation to ensure that the joint did not become fixed after the fracture healed. He refused both the operation and admission to a hospital bed and became abusive to the hospital staff. He was clearly in considerable pain and it was not possible to discuss the situation with him further. A full-length plaster was applied to the leg. In the opinion of the doctor this was the next best option. Mr Hall went home by ambulance with an appointment to attend the hospital for the plaster to be checked a week later.

$\mathrm{Mr}$ Hall lived alone in a council house in a rundown area of town. His wife had died six years previously. He had no contact with any relatives and nobody he regarded as a friend, although some of his neighbours came in to help him. The house was uncared for and he had not apparently washed or changed his clothes for some weeks. He supplemented his pension by accepting tips for the informal supervision of a car park or by begging. He greatly valued his ability to get about 
on his bicycle and was frightened that the accident would mean that he would have to go away to the place which he still identified as the workhouse, and which he refused to believe was no longer in use.

After coming home from casualty $\mathrm{Mr}$ Hall was visited by his general practitioner and district nurse and was offered the support of a social worker and home-help. He was also given a wheelchair so that he could get about indoors. He was very unpredictable about the help he would accept and would often not allow people into the house. He alternated between being un-co-operative and verbally aggressive, and complaining pathetically about his predicament. This was not a new pattern of behaviour, but an accentuation of what had developed over many years.

Mr Hall's next door neighbours would have nothing to do with him, so that he was convinced they wanted him out of his house.

When the ambulance came for his hospital appointment $\mathrm{Mr}$ Hall refused to go despite vigorous persuasion. He stayed at home and the combination of his immobility and a longstanding heart condition led to his foot becoming very swollen below the plaster. His condition deteriorated further and he was unable to lie down at night, because this led to heart failure which prevented him from breathing. He continued to refuse to go to hospital even though his life was becoming endangered. It was clear that he understood this, although he did not wish to die.

At this stage the community doctor was called to give advice whether $\mathrm{Mr}$ Hall should be compulsorily admitted to hospital under Section 47 of the National Assistance Act.

\section{Analysis}

In Mr Hall's case compulsory action had already been taken at an early stage in the initial treatment of his broken leg, and was now being contemplated again in relation to his possible removal to hospital. Given that it is generally accepted that medical treatment and care should not normally be instituted compulsorily, the question raised is whether there were special circumstances in Mr Hall's case which would justify compulsory action at the two stages identified.

There are well established though contrasting views as to how this question should be approached. The first relies on the traditional understanding of medical paternalism, which rests on the assumption that there are circumstances where the duty of the doctor is to take decisions for the patient without his consent, even though the patient has the capacity to make up his own mind and to express his wishes in this regard. The manner in which this is justified is to claim that doctors have a better perception of the patients' best interests than they have themselves. The evils prevented from occurring to patients are therefore considered greater than those caused by interference with their liberty. However, even if this perspective is accepted the problem remains of how to define and limit those situations where medical paternalism is warranted.
When considering paternalism in a general context, Gerald Dworkin argues that fully rational persons would take out a form of 'social insurance policy' to protect themselves against their own conduct which was potentially dangerous or where they did not fully appreciate the risks. He therefore concludes that we all ought to agree to have our actions controlled by others to a limited extent and that this can be put on a rational basis (2). Following this line of argument doctors embracing medical paternalism would claim that medicine is a precisely defined area of activity within which they are better placed than patients to make decisions, so it would be rational for people to concede autonomy to doctors, simply by becoming patients. These two interrelated ideas of a clearly demarcated medical realm in which doctors are best placed to make decisions, and therefore of the rationality of doctors deciding for patients, are frequently referred to by doctors in terms of their rights to 'clinical' and 'professional' freedom. This would seem to accord with Gerald Dworkin's view that there are certain areas which should be set aside for paternalistic decisionmaking. It is difficult though to see how such areas could be objectively specified in the way that Dworkin proposes for fully rational persons, because such persons would seem not to require the need for protection in the first place. In practice of course many areas of life are regulated by legislation so as to restrict the liberty of individuals in what is claimed to be theif best interest for example the complusory wearing of seat-belts. This is precisely because many people would not take action voluntarily, even though they are regarded as fully rational. The difficulty is to see why such rational people would wish to be forced into taking action when they decline to do so voluntarily, and why there should be considered to be a rational basis for deciding which areas should be selected for removal from the control of individuals.

In relating this to medicine the most ardent paternalist doctor would not claim that his decision should prevail in all medical circumstances. In fact doctors only tend to act paternalistically in particular areas of decision-making. For example if a young man with a family were to refuse treatment for a cancer for which the prognosis was poor and well-proven and successful treatment was available, few if any doctors would argue that he should be required to undergo treatment compulsorily, even though they considered his arguments for rejecting it to be extraordinarily misguided and eccentric. So it would appear that there is not a naturally defined medical sphere in which the decisions of doctors should rationally take precedence. Rather, in order to distinguish cases where the doctor is justified in overriding a patient's decision he must resort to the apparently paradoxical categorisation of the patient as 'competent but irrational', which although claiming to be logically derived is in practice a matter for medical discretion. Therefore if this reasoning were used in Mr Hall's case in deciding to act compulsorily, the doctor would in reality be claiming 
no more than that his view did not conform to that of $\mathrm{Mr}$ Hall and that in the particular set of circumstances it should prevail. The argument that the paternalist doctor could not sustain would be that such an action was rational simply because it was medical, and therefore it was in the best interests of the patient. The traditional understanding and use of the principle of beneficence in such circumstances has then been undermined.

An alternative approach to providing a justification for compulsory removal for treatment and care is that most commonly adopted in contemporary medical ethics. It starts from the premise that the doctor has the duty to respect the integrity and individuality of the patient, which entails a respect for the patient's autonomy. Autonomy is a form of personal liberty of action, where the individual determines his own course of action in accordance with a plan based on his own thoughts and decisions. The only justifiable restriction on this was described by J S Mill as follows:

'... the sole end for which mankind are warranted, individually or collectively, in interfering with the liberty of action of any of their number, is selfprotection. That the only purpose for which power can rightfully be exercised over any member of a civilised community, against his will, is to prevent harm to others. His own good, either physical or moral, is not a sufficient warrant' (3).

Therefore when dealing with an autonomous patient the doctor has a duty to obtain and respect the patient's informed consent to any proposed treatment or procedure. The only circumstances where this consent may be dispensed with, and so compulsory action be considered, is where the patient is a danger to others or is judged not to be autonomous because of incompetence through a lack of capacity. Determining the relevant concept of capacity and so the ability of the patient to give consent is clearly of crucial importance. Three different ways of doing so are commonly identified:

1) The content or outcome approach where the patient's capacity is judged by reference to the content of his decision, or the outcome which follows any particular decision. The problem with this though, is that a patient who makes a decision which is inconsistent with widely held values, or is otherwise unconventional, runs the risk of being labelled as, ipso facto, incapable of knowing his own mind and reaching his own decisions.

2) The status approach which relies on classifying groups of people, such as the mentally ill and handicapped, as lacking capacity by definition. One problem with this is that it is an all or nothing classification which rules out of consideration that people may have the capacity to make some decisions but not others. It also leaves open the possibility of people being labelled as mentally ill or handicapped by the application of the content or outcome approach.
3) The functional approach which depends on the ability of the particular patient to comprehend the nature and consequences of the proposed treatment or procedure.

From the point of view of patient autonomy it could be argued that only the third of these approaches can be justified because it is the only one which focuses on and respects each patient's individual ability. Problems however remain even with this functional approach, because a judgement still has to be made as to what it is for the patient to have properly understood the nature and consequences of any procedure. If this is rigidly construed it may turn out to be not very different from the content or outcome approach. On the other hand if it is interpreted more flexibly this may allow decisions to be taken which in some cases would threaten the future autonomy of the patient, for example if they involve the risk of death. It would seem therefore, that the notion of patient autonomy and the determination of capacity, which lies at the heart of the question as to when compulsory treatment and care can be justified, cannot be reduced to any ready-made set of ethical rules which are applicable in cases such as that of $\mathrm{Mr}$ Hall.

These two approaches to the justification of compulsory treatment and care, that of medica paternalism with its associated principle of beneficence, and of patient autonomy are frequentlo considered as opposites, but in their results they may only produce differences of emphasis. Ultimately they both relate to whether a patient's decision should be respected even though it is considered 'misguided', or whether it should not be respected because it is considered 'irrational'. It is merely the way in which this is framed which varies. Although to move from medical paternalism to patient autonomy takes the power to exercise discretion away from the exclusive control of doctors, it would not remove the need for discretionary judgement. The line to be drawn between decisions considered as misguided and irrational would continue to be open to different interpretations. Therefore neither approach has established a secure basis from which to derive ethically respectable decisions. Despite this there is usually a wide measure of agreement as to which criteria should apply in the average case, and it is only in difficult cases such as that of $\mathrm{Mr}$ Hall that this breaks down. Nevertheless these cases pose general questions as to how principles should be properly applied because they challenge widely-held assumptions.

A different perspective will therefore be adopted in analysing Mr Hall's case, one which does not start from particular theoretical premises but engages more directly with the details of the situation, the way in which they are understood, and the meaning which they provide. It is not a view which doctors are customarily encouraged to attend to in justifying their actions. This is made clear in an unusual revelation from a community doctor who was commenting on a 
case very similar to that of $\mathrm{Mr}$ Hall and in which he started with an analysis which parallels that which has been described already:

'Should a man like this be considered to be competent but misguided and therefore be removed by the community doctor because he is making a wrong decision? Or should he be considered to be incompetent by virtue of the fact that he is making an illogical decision in wishing to remain active but refusing to go to hospital, which is the only means that would enable him to regain his previous level of activity' (4)?

However, no attempt was made to resolve these questions, there was merely the conclusion that: 'I was unable to work out the precise reasons for my action on that hot Sunday afternoon in his small cramped room; but I decided to remove him compulsorily' (4). This suggests that a different mode of decision-making has been resorted to, and yet no explanation has been given for abandoning the original analysis, nor has it been made clear what has been substituted. An indication of what this different process might be can be found in the President's Commission Report which considered informed consent. It recognised that doctors' decisionmaking concerning informed consent does not and probably could not conform solely to sets of ethical and legal rules. Two of the observations on which this was based are particularly relevant. First that the more trust there is between doctor and patient the less disclosure there is, so that:

'... disclosure functions not to produce autonomy as the informed consent doctrine contemplates, but to produce trust that, once it exists, will then permit the doctor to dispense with further explanation' (5).

Secondly that:

'Fundamentally, patients feel that they are unequal to the task of making medical decisions, even when provided with information to do so' (6).

These comments suggest that the process of communication between doctor and patient establishes trust between them, and that communication so developed is not primarily about the passing on of relevant information, nor is such information typically used by the patient in decision-making. So even in relatively straightforward cases the characteristic understanding of informed consent and its derivation from patient autonomy must be modified.

This is of importance to $\mathrm{Mr}$ Hall's case as throughout his ordeal the salient feature of his relationships with all those involved was a deep distrust of their motives. When he first arrived at the casualty department he was very distressed when he found himself confronted by the hospital staff, who took it for granted that he would not question their advice for him to be admitted to hospital for operation. His refusal was therefore met with incomprehension, which was only heightened by his further rejection of a leg plaster.
In these circumstances and in the clinical atmosphere of the casualty department there was no possibility that any real communication or trust could have been established. The very idea of attempting to obtain informed consent in such a situation would seem empty of meaning. To the staff it was simply imperative that if $\mathrm{Mr}$ Hall were to go home he should receive treatment at least to alleviate his pain and stabilise his leg. That was considered reason enough. Later on when $\mathrm{Mr}$ Hall was at home and refused to return to hospital the circumstances were very different, because although his life was threatened the danger was not immediate. In fact the prospect was that his condition would slowly deteriorate and he would suffer worsening pain and discomfort, and a lingering death. So there was time for the situation to be discussed with him over a period of days before any final decision had to be taken. When the community doctor was called to give advice, $\mathrm{Mr}$ Hall had already been subjected to a considerable amount of pressure from his general practitioner, social worker and various neighbours to persuade him to go to hospital. However, this only seemed to have confirmed him in his resolve not to do so. It was as if by resisting and denying the need for help he was able to draw psychological strength. Therefore the community doctor's approach was to avoid confronting him directly and to attempt to understand his concerns and the reasons for them.

As described earlier, $\mathrm{Mr}$ Hall had an ambivalent relationship with his neighbours. It seemed that on the one hand he wanted assistance from them, but on the other hand despised the feeling of being the object of pity and charity. He also both 'earned' a little money and begged, so that again he accepted charity but despised it simultaneously. To most people he would have appeared as socially undesirable and a burden on others, but he strove, however unsuccessfully, to maintain his dignity and independence. His life was a constant struggle to achieve recognition of his worth. His accident epitomised this struggle, and was for him a moral as much as a physical crisis. By endangering the use of his leg it threatened his mobility and his independence, but the means to healing his leg he regarded as an even greater threat to his independence, because it involved admission to the hospital which he still identified as the workhouse, the very symbol of social degradation and dependence. Faced with this conflicting prospect he relied on a familiar pattern of response, that of boosting his courage by denying the need for help. Mr Hall saw this as a means of affirming his independence and dignity in what he felt to be assaults upon them from the way that others disagreed with him, cajoled him and insisted that he was wrong. Even in such an extreme situation, where he appreciated that his life was at risk, he still gave precedence to the struggle for recognition of his human worth. It was also through that struggle that he was able to sustain a tenacity for life which helped him to cope with his physical ordeal. 
Any attempt by the community doctor to reason with $\mathrm{Mr}$ Hall about the fact that the hospital he would be taken to was not as he thought, and that he would not be held there long-term or submitted to an operation against his will, would not only have been fruitless, but would have served to convince him that this was indeed what was being planned for him. So although a degree of communication was established, the inevitability of this finally leading to a decision about hospitalisation prevented it developing into a relationship of trust, and after several long discussions Mr Hall had not changed his position. What had become evident to the community doctor though was the understanding that $\mathrm{Mr}$ Hall had of his own position, which could only be appreciated once his social position and personal perspective were taken seriously. The ethical dilemma for the community doctor was how to respond to Mr Hall's refusal of treatment and care in such a way as to embody this understanding. Simply to judge Mr Hall's refusal of care as irrational would be to dismiss the insights gained into his own reasoning and so to discount them. Yet the alternative would entail accepting his decision because it could never be judged to be wrong as long as the consequences only affected him. From this position there could be no criteria for determining whether such a decision was right or wrong, the fact of the patient having made it being all that was required for it to be correct.

\section{Conclusion}

The resolution of this ethical dilemma requires a different moral conception, involving the recognition that there is an inevitable conflict of view between the patient and the community doctor, and that both sides be respected by being taken seriously.

The problem which this poses though, is that although the rational use of ethical principles as commonly applied to medicine has been shown to be unwarranted, to resort solely to a personal ethics offends against our sense that morality requires consistency, and so it appears to endorse prejudice. The choice would seem to lie between rational principles and individual prejudices, neither of which provides an acceptable answer. Nevertheless a decision still has to be taken and hence a judgement has to be made.

If it is not to be arbitrary it requires a method of procedure and justification which must properly take account of these issues.

Toulmin claims that the personal must take precedence and not be made to conform to principles, because we

'need to recognise that a morality based entirely on general rules and principles is tyrannical and disproportioned, and that only those who make equitable allowances for subtle individual differences have a proper feeling for the deeper demands of ethics' (7).

It is this disquiet that the application of principles will be used to allow personal ethical sensitivity to be ignored or suppressed which must be taken very seriously. Cassell draws attention to one reason why this is so difficult to accept in relation to the practice of medicine. It is because the whole basis of medical science and methodology is to eliminate human bias, individual or institutional, to prevent distortion of the findings by the particular beliefs or values of the investigator. But he argues that progress in medical care, even in research, requires not further freedom from value contamination, but rather the intensive pursuit of the valuing subject, and he concludes that '... a value-free human medicine, a medicine free of meaning to the subject is impossible - it is, in fact, a contradiction in terms', because 'medical practice is ineluctably subjective, subordinate to the human values and personal meaning of both physicians and patients' (8).

This recognition of the inseparable place of subjectivity in medical practice undermines any possibility of discovering a purely rational method of determining whether in Mr Hall's case his decisions about his own treatment and care should be accepted or not. If his subjective understanding is to be taken seriously there cannot be an objective standard which will provide a necessarily correct ruling. What this does not mean though, is that Mr Hall's decision has any absolute status either, simply that in deciding on the right course of action it must be taken seriously, and this is the important sense in which recognition of personal subjectivity leads to a true respect for persons without being just an endorsement of prejudice. It follows that all the decisions of human beings deserve respect even when they are not considered rational or benevolent, and also that they should be entitled to respect even though they are not always compatible with one another. As Isaiah Berlin argues 'the possibility of conflict - and of tragedy - can never wholly be eliminated from human life, whether personal or social' (9). Consequently there can never be an ethical theory or scheme which will resolve all conflicts. What is required is that such conflicts are not used as a pretext for suppressing or ignoring some of the moral concerns which are involved, by prejudging the way in which they are to be viewed.

Hence in cases such as that of $\mathrm{Mr}$ Hall, where the interpretation of his wishes is itself uncertain, it would appear that a judgement has to be made on his behalf and even when the patient's wishes are clear it may still sometimes be appropriate. This is a role that has traditionally fallen to the doctor, and the issue is not so much which decision is finally taken, although this is clearly important, but to establish which, if any, cases should properly fall into this category. Those who deny the need for such proxy decision-making at all and describe it as paternalistic and as overriding patient autonomy, are misinterpreting the process that is involved. When a person's capacity cannot be determined by reference to particular standards, without destroying that person's moral integrity, to 
make a decision on that person's behalf may not be to deny that integrity but to respect it. The emphasis though must be on the manner of the process leading to the decision to act compulsorily and how the decision was actually taken. It must be one of compassion through the decision-maker becoming involved with and responding to that person's dilemma. No doctor entrusted with such authority can reach a proper decision if he is dismissive of that patient's concerns, one outcome of which might be that he improperly designates those with capacity as being incompetent. In this last respect doctors have often been correctly accused of paternalism and the problem raised here is how to distinguish unjustified paternalism from the proper need for decisions by proxy. The point is that the distinction can only be made on the basis of trust and good faith, and so of discretionary judgement, because it is in the very nature of such difficult cases that the dividing line cannot be established precisely.

Jacob describes how this comes about:

'It may be agreed that "we" have to agree on common standards. In the face of the impossibility of finding the means to do so, we adopt an agreed procedure to define them ... . It is procedure, not reason, which makes us accept their (the doctors') verdicts. They give us the "right" answers because we give them the job of defining answers: they define them for the simple reason that our needs require a definition and our procedure gives that task to them' (10).

What follows is that doctors or some other appropriate authority sanctioned by society are both necessary and justified in determining the use of compulsory removal in a few cases, such as that of $\mathrm{Mr}$ Hall, which involve adults who are not mentally incapacitated and hence incompetent as customarily defined.

In these cases to seek for an objectively 'correct' decision has no meaning, and this is why a judgement by an authorised decision-maker is unavoidable. The rightness of this judgement does not depend then, simply on which decision is made, but on the way in which it is taken.

The analysis of Mr Hall's case suggests that resort to principles of beneficence (and so of justified medical paternalism) or of patient autonomy, or any other principles is inadequate in attempting to resolve the dilemma of whether his compulsory removal is morally acceptable. It must also be recognised that this may apply in some circumstances to other parallel cases involving decisions about the compulsory management of competent patients, for example force-feeding of political prisoners who are on hunger strike and starving to death. One solution would be to make all such practices involving compulsion unlawful but to do so would not resolve the ethical dilemma, but simply obviate it. The right approach should be to provide a framework of law which matches the appraisal outlined above by recognising that there is no complete set of rules sufficient properly to express all the moral concerns which may arise. It is precisely the diversity and potentially conflicting nature of the moral considerations involved in particular cases which defies their being captured in any wholly rational moral scheme. Hence there is a necessary element of uncertainty which means that the question of competence cannot always be definitely determined, so that there must be the possibility of compulsory removal being judged appropriate. It follows that if the law is to reflect this it must be permissive enough to allow for that possibility, whilst also taking account of the potential dangers of making compulsory removal too easy. Hence passing such a law requires that, on the one hand, the boundaries of the categories of people to be included under it are not absolutely defined, whilst on the other hand those same categories are restricted and limited to some extent. This is because those authorised as decision-makers inevitably play a part in determining such definitions, through their involvement with people being considered as possible subjects of the law. What the law cannot do in balancing these concerns is to provide definitive guidance as to how the community doctor should act, as it can only be sensitive and just through permitting him some degree of interpretation of its categories. Equally it would only operate in this manner if the process of interpretation and the final judgements made in each case were carried out with mora integrity.

\section{Acknowledgement}

I wish to thank Derek Morgan for his comments on this paper.

David A Greaves is Fellow in Philosophy and Health Care at the Centre for Philosophy and Health Care, University College, Swansea.

\section{References and notes}

(1) Muir Gray J A. 'Section 47': an ethical dilemma for doctors. Health trends 1980; 12: 72-74.

(2) Dworkin G. Paternalism. The monist. 1972 Jan: 68-84.

(3) Mill J S. On liberty. In: Warnock M, ed. Utilitarianism Glasgow: Collins/Fontana, 1974: 135.

(4) Muir Gray J A. The ethics of compulsory removal. In Lockwood M, ed. Moral dilemmas in modern medicine. Oxford: Oxford University Press, 1985: 107.

(5) The President's Commission Report. Making health care decisions: appendix $C$. Washington DC: US Government Printing Office, 1982: 402.

(6) See reference (5): 403.

(7) Toulmin S. The tyranny of principles. Hastings Center report, 1981; 11: 31-39.

(8) Cassell E J. Uses of the subjective in medical practice. In: Cassell E J, Siegler M, eds. Changing values in medicine. Frederick, Md: University of America Publications Inc, 1985: 156-157.

(9) Berlin 1. Two concepts of liberty. Oxford: The Clarendon Press, 1958: 54.

(10) Jacob J M. Doctors and rules. London and New York: Routledge, 1988: 172. 